\title{
What Social Security: Beveridgean or Bismarckian?*
}

\author{
J. Ignacio Conde-Ruiz \\ Universitat Pompeu Fabra \\ Paola Profeta \\ Università Bocconi and Università di Pavia
}

July 2002

\footnotetext{
${ }^{*}$ Corresponding author: Paola Profeta, Address: IEP-Università Bocconi. Via Gobbi, 5,20136 Milano (Italy), Phone number: +39 0258365332, Fax number: +39 0258365318, Email: paola.profeta@uni-bocconi.it. J. Ignacio Conde-Ruiz, Department of Economics, Universitat Pompeu Fabra, Ramon Trias Fargas, 25-27. 08005 Barcelona, Spain, E-mail: ignacio.conderiuz@econ.upf.es. We thank Vincenzo Galasso for his help and support throughout the entire project. We are grateful to Tito Boeri and Fondazione Rodolfo De Benedetti to provide us with the EHCP data and especially to Mauro Maggioni to help us with the merge of the data. We are also grateful to Pierre Pestieau for a useful talk and to Franco Peracchi and Ernesto Villanueva for helpful comments. All remaining errors are ours.
} 


\begin{abstract}
Why are Bismarckian social security systems associated with larger public pension expenditures, a smaller fraction of private pension and lower income inequality than Beveridgean systems? These facts are puzzling for political economy theories of social security which predict that Beveridgean systems, involving intragenerational redistribution, should enjoy larger support among low-income people and thus be larger. This paper explains these features in a bidimensional political economy model. In an economy with three income groups, low-income support a large, redistributive system; middle-income favor an earning-related system, while high-income oppose any public system, since they have access to a superior saving technology, a private system. We show that, if income inequality is large, the voting majority of high-income and low-income supports a (small) Beveridgean system, and a large private pillar arises; the opposite occurs with low inequality. Additionally, when the capital market provides higher returns, a Beveridgean system is more likely to emerge.
\end{abstract}

Keywords: Political economy; public versus private social security; pensions systems across european countries; income inequality, structure-induced equilibrium.

JEL Classification: H53, H55, D72. 


\section{Introduction}

All developed countries have a Social Security system. However, the size of the social security systems varies across countries: in 1995, they absorbed $4.5 \%$ of GDP in the US, $5.54 \%$ in the Netherlands, $4.6 \%$ in the United Kingdom and $9 \%$ in Italy, $7.5 \%$ in France and over 7\% in Germany.

There are also many different features in the design of social security systems. Focusing on European countries, Italy, France and Germany have very high replacement rates at all levels of income, while the UK and the Dutch systems provide lower replacement rates for higher earners than for lower earners (see Disney and Johnson 2001). This implies that the former countries have a social security system which does not redistribute within cohort, while the latter ones appear to be quite redistributive. In other words, the former countries are of a "Bismarckian" type (there is a tight link between contributions and benefits, and thus low redistribution) and the latter are "Beveridgean" (benefits are quite flat and contributions are proportional to earnings, thus redistribution is large).

Since the "Bismarckian" systems have typically a larger size, a puzzle arises. Political economy theories of social security (see Galasso and Profeta 2002 for a review) suggest that Beveridgean systems, involving intragenerational redistribution, should enjoy larger support among low income people than Bismarckian ones, which do not entail any intragenerational redistribution, and should thus be larger.

Previous contributions to solve this puzzle in the literature of political economy models of social security are Casamatta, Cremer and Pestieau (1999), Cremer and Pestieau (1998) and Pestieau (1999). However, they analyze the effect of the design of the benefit formula (Bismarckian versus Beveridgean) on the optimal size of the social security system, without explaining why a Bismarckian or a Beveridgean system with the features that we observe may arise, or they focus on the implications of the different systems for labor mobility across countries.

The aim of this paper is to provide a positive theory of the redistributive 
design of the social security systems which accounts for many of the different characteristics of the alternative systems, such as the benefit formula (Bismarckian or Beveridgean), the size and relevance of the second pillar.

We first perform an empirical analysis based on the data of the European Commission Household Panel (1993-1996) to confirm the existence of such a puzzle. We divide the total population in three income groups of equal size and construct a "Beveridgean" index as the average of the differences in the replacement rates for people of different levels of income. As expected, countries that show higher values of this index (such as the UK) are associated with lower public pension expenditures, than countries that are more Bismarckian (Italy, France).

To explain this puzzle we develop a bidimensional political economy model. In our overlapping generations model, there exist three income groups, with different access to the capital market: low income people face a lower interest rate than middle income people, who in turn face a lower interest rate than high income people. People vote contemporaneously on two dimensions of the social security system: the pension level of the low income group, and the degree of intragenerational transfer in the benefit formula. The latter feature is captured by a Bismarckian factor, $\alpha$, which represents the part of the pension depending on the average earnings rather than on each individual's earning. It is well known that in a multidimensional issue space Nash equilibrium of a majoritarian voting game may fail to exist. The literature provides different alternatives to solve this problem: structure induced equilibrium, probabilistic voting, veto power or legislative bargaining and lobbying (see Persson and Tabellini, 2000). In this paper we use the concept of structural induced equilibrium (as in Conde Ruiz and Galasso 1999, 2000). We show that low income people support a large, highly redistributive system (Beveridgean); middle income people favor an earning-related system (Bismarckian), while high income people oppose any public social security system, since they have access to a superior saving technology, e.g. a private system. Thus, aggregating preferences, the following equilibrium of the voting 
game arises. If income inequality is large, high income individuals join the low income people in a voting majority that supports a Beveridgean system, with a high level of pension for the low income individuals. The overall size of the system is however small, and a large private pillar arises. If income inequality is small, middle income people represents a majority which sustains a Bismarckian system, with a lower level of the pension for the low income people, and a larger size of the system. This leads to a smaller size of the private pillar.

These predictions are finally empirically tested. First, our calculations on ECHP data show that Beveridgean social security systems tend to guarantee higher replacement rates to low income individuals than Bismarckian ones. Second, we report data from the World Development Indicators of the World Bank (2000) to show that countries with Bismarckian systems have lower income inequality than Beveridgean ones. Third, we gather additional empirical evidence to show, as expected, that Bismarckian social security systems are typically associated with a smaller fraction of private pension (second pillar) than Beveridgean ones. In fact, the existence of a large public PAYG system leaves a limited space to the development of the second pillar. The majority of the elderly rely uniquely on the public pension, but the high replacement rates guarantee them a standard of living almost equal to the one they had during their working life, and thus reduces the need of complementary private pensions. Moreover, Beveridgean systems are typically associated with higher returns from the private pensions in the capital market.

The paper is organized as follows: the next section provides an empirical assessment of the "puzzle". The following sections introduce the economic environment, the voting game and the politico-economic equilibria. Finally, we empirically test the predictions of the model. All proofs are in the appendix. 


\section{Empirical Motivations}

In this section we perform an empirical analysis using data form the European Commission Household Panel (ECHP) for years from 1993 to 1996 (4 waves).

The ECHP provides data on personal wage-salary earnings and pensions, together with many personal informations for a sample of individuals in the following European countries: Denmark, Netherlands, Belgium, Luxembourg, France, United Kingdom, Ireland, Italy, Greece, Spain, Portugal, Austria, Finland and Sweden $^{1}$. For each country, we merge the data of two successive waves and calculate the replacement rates, defined as the ratio of post-retirement pension benefits to pre-retirement earnings. Similarly to Nicoletti and Peracchi $(2001,2002)$ the replacement rates are calculated by using the four waves of the ECHP and the subsample of people aged 55-69 at the time of retirement ${ }^{2}$. The data contain the information on self-reported main activity status in each month, with retirement being one of the alternative activity status. This information allows us to select the individuals who retired in any month between February 1993 and December 1996. For people who retired in year $t(\mathrm{t}=1993,1994,1995,1996)$, the replacement rate is computed as the ratio of monthly pension benefits in year $t$ (annual pension income in year $t$ divided by the number of months during which the person was retired) and monthly earnings in year $t-1$ (annual earnings divided by 12). Pension income only includes old-age pensions, and earnings are the wage and salary earnings, net of taxes and social security contributions (with the exception of France, where income is gross $\left.{ }^{3}\right)$. The replacement rates for the Netherlands and Sweden are not computed, since for Netherlands the monthly information on

\footnotetext{
${ }^{1}$ For a detailed description of the ECHP data see Peracchi (2002) and Nicoletti and Peracchi (2001, 2002).

${ }^{2}$ We simplify their procedure, and adopt also for intermediate years the same way to calculate the replacement ratio that they use for those retired in the first and the last year of the considered period.

${ }^{3}$ The gross value in France does not affect the replacement rate, as long as the ratio between net and gross earnings is equal to the ratio between net and gross pension benefits, as explained by Nicoletti and Peracchi (2002).
} 
activity status is not available, and for Sweden the first available data are the ones of 1996 and we thus still do not have any longitudinal information in the 4 waves available to us. Pooling for each country the replacement rates for individuals retiring at any month in the considered period, our sample sizes are still quite small, ranging from a maximum of 336 observations in Italy to a minimum of 15 observations in Finland.

We then divide these observations in three income groups, taking a constant number of observations for each group and calculate the median ${ }^{4}$ replacement rate for each income group. How the replacement rates vary across income groups depends on the country. We thus construct a "Beveridgean" index as the average between the differences of the replacement rates by income groups (difference between the replacement rate of the low and the middle income, the middle and the high, the low and the high). Table 1 shows the results. As expected, the UK and Luxembourg have a higher Beveridgean index, followed by Denmark, while France, Italy and Spain show lower values, and they are thus more Bismarckian.

Table 2 shows OECD data on the evolution of pension expenditures in European Countries (as \% of GDP). The United Kingdom, Luxembourg, Netherlands and Belgium enjoy lower pension expenditures than Italy, France and Spain. Comparing tables 1 and 2, and having in mind that Netherlands are usually believed to have a Beveridgean system (see Disney and Johnson 2001), it appears that more Beveridgean countries are typically associated with lower public pension expenditures than Bismarckian ones.

This evidence raises the puzzle and motivate our following analysis: why are Bismarckian systems associated with larger public pension expenditures? According to the political economy literature on social security, we should expect that Beveridgean systems are supported also by low-income individuals and should thus be larger. What are the additional characteristics of the systems which may drive this apparently "puzzling" result?

\footnotetext{
${ }^{4}$ The median is less affected than the mean by the existence of atypical data. Notice that Nicoletti and Peracchi $(2001,2002)$ also use a median regression model.
} 


\section{The Economic Environment}

We consider a two period overlapping generations model. Every period two generations are alive: Young and Old. Population grows at a constant rate, $n>0$. There are three types of agents $(j)$ : low, middle and high ability $(j=L, M, H)$. The size of each group may differ, and the proportions of each group are indicated respectively by $\rho^{L}, \rho^{M}$ and $\rho^{H}$. Each group may not be larger than $1 / 2$ : $\rho^{j}<1 / 2$. Their working abilities correspond to their wage, and are respectively $w^{L}, w^{M}$ and $w^{H}$, with $w^{L}<w^{M}<w^{H}$. We call $\bar{w}$ the mean wage income, $\bar{w}=\rho^{L} w^{L}+\rho^{M} w^{M}+\rho^{H} w^{H}$, which may be larger or smaller than $w^{M}$.

Agents maximize a standard utility function depending only on consumption in the two periods ${ }^{5}$. As in Casamatta, Cremer and Pestieau (2000), we assume that the utility function has constant elasticity of substitution between consumption in period $t$ and period $t+1$ equal to $1 / \gamma$, with $\gamma>1$. Young agents pay a proportional tax, $\tau_{t}$, on their wage income and decide to save a part of their wage income for their old age. We assume that the three groups have different access to the capital market. In particular, low income people face a lower interest rate than middle income people, who in turn face a lower interest rate than high income people. This assumption reflects the imperfection in the capital market, and it allows us to differentiate the access to the private pension pillar by income groups. We assume that the middle income group faces an interest rate which is equal or higher to the implicit average rate of return from the social security system, i.e. in our case, to the population growth rate, while the low-income group faces an interest rate which is lower than the return from the PAYG system. Therefore,

\footnotetext{
${ }^{5}$ This is a quite restrictive assumption, since we cannot analyze the trade-off between consumption and leisure and the choice of retirement for elderly people. Notice that a model with leisure would imply a distortionary effect of taxes which would reinforce our results. When there is a link between the labor history of a worker and his final pension (Bismarckian system), the distortion of the payroll tax on the labor-leisure decision is lower than it is when such a link does not exist (Beveridgean system). Therefore in a model with labor-leisure decision, pensions are less costly, in terms of deadweight loss from taxation, in a Bismarckian scheme than in a Beveridgean one.
} 
an individual of ability $j$ who save 1 euro in period $t$ will have a return of $\left(1+r^{j}\right)$ euro in period $t+1$, with $r^{L}<n \leq r^{M}<r^{H}$.

Old agents do not work ${ }^{6}$. They receive a pension transfer, whose amount could depend on their wage, as it will be specified below. We call $p_{t}^{j}$ the pension awarded at time $t$ to a $j$-type old agent.

The representative type- $j$ young agent in period $t$ solves the following problem:

$$
\max _{\substack{t, j \\ c_{t}^{t, j}, c_{t+1}^{t, j}}} U\left(c_{t}^{t, j}, c_{t+1}^{t, j}\right)=\frac{\left(c_{t}^{t, j}\right)^{1-\gamma}}{1-\gamma}+\beta \frac{\left(c_{t+1}^{t, j}\right)^{1-\gamma}}{1-\gamma}
$$

subject to the individual budget constraint:

$$
\begin{aligned}
c_{t}^{t, j}+s_{t}^{j} & \leq w_{t}^{j}\left(1-\tau_{t}\right) \\
c_{t+1}^{t, j} & \leq s_{t}^{j}\left(1+r^{j}\right)+p_{t+1}^{j} \\
0 & \leq s_{t}^{j}
\end{aligned}
$$

where $0<\beta \leq 1$ is a factor of time preference and $\gamma>1$ is the coefficient of relative risk aversion, superscripts indicate the period when the agent was born and subscripts indicate the calendar time.

Notice that the restriction on non-negative savings $\left(s_{t}^{j} \geq 0\right)$ rules out the possibility of borrowing in youth against future pension payments. It is easy to show that the saving decision of any type- $j$ individual yields the following condition:

$$
s_{t}^{*, j}=\left\{\begin{array}{ccc}
0 & \text { if } & \beta\left(1+r^{j}\right)<\left(\frac{p_{t+1}^{j}}{w_{t}^{j}\left(1-\tau_{t}\right)}\right)^{\gamma} \\
\frac{w_{t}^{j}\left(1-\tau_{t}\right)\left(\beta\left(1+r^{j}\right)\right)^{\frac{1}{\gamma}}-p_{t+1}^{j}}{\left(1+r^{j}\right)+\left(\beta\left(1+r^{j}\right)\right)^{\frac{1}{\gamma}}} & \text { otherwise }
\end{array}\right.
$$

where savings are increasing in the interest rate and in disposable wage income and decreasing in the pension transfer.

\footnotetext{
${ }^{6}$ See the previous footnote.
} 


\subsection{The Social Security System}

We consider a pay as you go (PAYG) social security system, in which workers contribute a fixed proportion of their labor income to the system, and the proceedings are divided among the old. Following Pestieau (1999) we assume that a type- $j$ retired person receives a pension, $p_{t+1}^{j}$ which consists on two parts: i) a contributory part which is directly related to individual earnings, $w^{j}$; and ii) a non-contributory part which depends on average earnings, $\bar{w}$. The system is assumed to be balanced every period, so that the sum of all awarded pensions is equal to the sum of all received contributions. Therefore, the average return from the social security system is given by the population growth rate. These properties yield the following expression for a pension received by a type- $j$ pensioner:

$$
p_{t+1}^{j}=(1+n) \tau_{t+1}\left(\alpha_{t+1} w^{j}+\left(1-\alpha_{t+1}\right) \bar{w}\right)
$$

The parameter $\alpha_{t+1}$ is the Bismarckian factor, that is the fraction of pension benefits that is related to contributions. As in Casamatta, Cremer and Pestieau (1999) we assume $0 \leq \alpha \leq 1$. When $\alpha=1$ the pension scheme is contributory or purely Bismarckian; and when $\alpha=0$ pension benefits are uniform and the scheme is purely redistributive or Beveridgean. For intermediate values, $0<\alpha<1$, due to the combination of a proportional labor income tax and the non-contributory part, there exist an element of within cohorts redistribution, from rich to poor, which is higher the lower is the Bismarckian factor (the lower $\alpha$ ). As in Tabellini (2000) and Conde-Ruiz and Galasso (1999), this feature can be crucial in our political game, because it may induce low ability young to support the social security system even when the average return of pensions is lower than the average return of private savings ${ }^{7}, n<r^{L}$.

The PAYG social security budget constraint is the following:

$$
\sum_{j=\{L, M, H\}} \rho^{j} p_{t}^{j}=(1+n) \tau_{t} \bar{w}
$$

\footnotetext{
${ }^{7}$ Evidence in favor of the existence of this within-cohort redistribution for the US system can be found in Boskin et al. (1987) and Galasso (2002).
} 
In every period, the social security system can be characterized by a triple: the pension received by the low-income individuals, the payroll tax rate, and the Bismarckian factor, $\left(p^{L}, \tau, \alpha\right)$. Disney et al. (1998) suggest that the pension level of the low-income individuals represent a key component of the redistributive structure of the system. Thus, we decide to characterize the social security system by the pension received by low-income individuals and by the Bismarckian factor. Once the minimum pension and the Bismarckian factor are determined, using the PAYG budget constraint, the tax rate is also fully characterized. In other words, for a given $p_{t+1}^{L}$ and $\alpha_{t+1}$, we have that:

$$
\tau_{t+1}=\frac{p_{t+1}^{L}}{(1+n)\left(\alpha_{t+1} w^{L}+\left(1-\alpha_{t+1}\right) \bar{w}\right)}
$$

and the pensions for the middle and high type are respectively:

$$
\begin{aligned}
p_{t+1}^{M} & =\frac{\left(\alpha_{t+1} w^{M}+\left(1-\alpha_{t+1}\right) \bar{w}\right)}{\left(\alpha_{t+1} w^{L}+\left(1-\alpha_{t+1}\right) \bar{w}\right)} p_{t+1}^{L} \\
p_{t+1}^{H} & =\frac{\left(\alpha_{t+1} w^{H}+\left(1-\alpha_{t+1}\right) \bar{w}\right)}{\left(\alpha_{t+1} w^{L}+\left(1-\alpha_{t+1}\right) \bar{w}\right)} p_{t+1}^{L}
\end{aligned}
$$

Notice that if the system is purely Beveridgean, $\alpha=0$, pensions are equal across types, $p_{t+1}^{L}=p_{t+1}^{M}=p_{t+1}^{H}$, while the replacement rates $\left(p_{t+1}^{j} / w^{j}=(1+n) \tau_{t+1} \bar{w} / w^{j}\right.$ $\forall j=L, M, H)$ are decreasing in labor income. On the other hand, if the system is purely Bismarckian, $\alpha=1$, pensions are increasing in labor income, $p_{t+1}^{L}<p_{t+1}^{M}<$ $p_{t+1}^{H}$, while the replacement rates are equal across types $\left(p_{t+1}^{j} / w^{j}=(1+n) \tau_{t+1}\right.$ $\forall j=L, M, H)$.

\subsection{The Economic Equilibrium}

The following definition introduces the economic equilibrium, given the values of the social security system, which will be determined by the political game.

Definition 3.1. For a given sequence $\left\{\tau_{t}, \alpha_{t}, p_{t}^{L}\right\}_{t=0}^{\infty}$, exogenous interest rates, $r^{L}, r^{M}$ and $r^{H}$, an economic equilibrium is a sequence of allocations, $\left\{\left(s_{t}^{j}, c_{t}^{t, j}\right.\right.$, $\left.\left.c_{t+1}^{t, j}\right)\right\}_{j=\{L, M, H\}}^{t=0, . ., \infty}$, such that: 
- In every period agents solve the consumer problem, i.e., every type $j$ young individual maximizes her utility function $U\left(c_{t}^{t, j}, c_{t+1}^{t, j}\right)$ with respect to $s_{t}^{j}$, and subject to the individual budget constraints;

- The social security budget constraint is balanced every period;

- The goods market clears every period:

$$
\sum_{j=\{L, M, H\}}(1+n)\left[\rho^{j} c_{t}^{t, j}+\rho^{j} c_{t}^{t-1, j}\right]=\left(\rho^{L} w^{L}+\rho^{M} w^{M} \rho^{H} w^{H}\right)(1+n)
$$

The life-time utility obtained in equilibrium by a type $j$ young agent and the remaining life-time utility for a type $j$ old agent are represented respectively by the following indirect utility functions:

$$
\begin{gathered}
v_{t}^{t, j}\left(p_{t}^{L}, \alpha_{t}, p_{t+1}^{L}, \alpha_{t+1}\right)=\frac{\left(w_{t}^{j}\left(1-\tau_{t}\right)-s_{t}^{j *}\right)^{1-\gamma}+\beta \frac{\left(s_{t}^{j *}\left(1+r^{j}\right)+p_{t+1}^{j}\right)^{1-\gamma}}{1-\gamma}}{1-\gamma} \\
v_{t}^{t-1, j}\left(p_{t}^{L}, \alpha_{t}\right)=\frac{\left(K_{t}^{j}\left(1+r^{j}\right)+p_{t}^{j}\right)^{1-\gamma}}{1-\gamma}
\end{gathered}
$$

where $s_{t}^{j *}$ is the optimal level of saving obtained at equation $3.3, \tau_{t}$ is a function of $p_{t}^{L}$ and $\alpha_{t}$ by equation $3.6, p_{t+1}^{j}$ and $p_{t}^{j}$ are functions of $p_{t+1}^{L}, \alpha_{t+1}$ by equations 3.7 , and $K_{t}^{j}$ is a constant which does not depend on current or future values of the social security system ${ }^{8}$.

\section{The Political Institution}

The size and composition of the social security system are determined through a political process which aggregates agents' preferences over the minimum pension, $p^{L} \geq 0$, and the Bismarckian factor, $\alpha \in[0,1]$.

Since the issue space is bidimensional ( $p^{L}$ and $\alpha$ ), Nash equilibrium of a majoritarian voting game may fail to exist. The literature provides alternative solutions

\footnotetext{
${ }^{8}$ Specifically, $K_{t}^{j}=s_{t-1}^{j}\left(1+r^{j}\right)$.
} 
(see Persson and Tabellini, 2000): probabilistic voting, lobbying, structure induced equilibrium, agenda setting. We adopt a majoritarian voting system and use the concept of structure induced equilibrium. This equilibrium concept is based on Shepsle (1979) and it has been used in the context of political economy models of social security by Conde-Ruiz and Galasso (1999, 2002). As in their papers, our game is intrinsically dynamic, since it describes the interaction between successive generations of workers and retirees. We therefore use their concept of subgame perfect structure induced equilibrium ${ }^{9}$, which reduces the game to a dynamic issue-by-issue voting game.

Elections take place every period. All persons alive, young and old, simultaneously cast a ballot over the two dimensions separately, $p^{L}$ and $\alpha$. Since every agent has zero mass, no individual vote could affect the outcome of the election. We assume sincere voting. The two dimensions can be interpreted as two different jurisdictions. One of them has to decide over $p^{L}$, and the other over $\alpha$. The decision is the outcome of separate votes, one over each dimensions.

First, we analyze the case of full commitment, in which voters determine the constant sequence of the parameters of the welfare state $\left(p^{L}, \alpha\right)$. In other words, current voters can determine future policies. In the absence of a state variable, this voting game is static, and the result in Shepsle (1979) [Theorem 3.1] can be applied to obtain the sufficient conditions for a (structure induced) equilibrium to exist. In particular, if preferences are single-peaked along every dimension of the issue space, a sufficient condition for $\left(p^{L *}, \alpha^{*}\right)$ to be an equilibrium of the voting game with full commitment is that $p^{L *}$ represents the outcome of a majority voting over the jurisdiction $p^{L}$, when the other dimension is fixed at its level $\alpha^{*}$, and viceversa. ${ }^{10}$

Second, we show that the (structure induced) equilibrium outcomes of the

\footnotetext{
${ }^{9}$ See the appendix for a formal definition, and Conde-Ruiz and Galasso (2002) for a detailed discussion.

${ }^{10}$ See Persson and Tabellini (2000) for a simple explanation of how to calculate a structure induced equilibrium.
} 
game with commitment are also subgame perfect equilibrium outcomes of the voting game without commitment ${ }^{11}$. In the game with no commitment, voters may only pin down the current values of $p^{L}$ and $\alpha$, although they may expect their current voting behavior to affect future voters' decisions.

We start from the case of commitment. Individuals' votes over each dimension of the issue space, $\left(p^{L}, \alpha\right)$, are examined issue-by-issue. Voters cast a ballot over a constant sequence of $p^{L}$, for a given constant sequence of $\alpha$, and viceversa. For each dimension, $p^{L}$ and $\alpha$, votes are then ordered to identify the median voter, which represents the structure induced equilibrium outcome of the voting game with commitment. Thus, for each $\alpha$, we identify the median voter for $p^{L}$, and, for each $p^{L}$, we identify the median voter for $\alpha$. The points at which these median functions intersect, $\left(p^{L *}, \alpha^{*}\right)$, represent the (structure induced) equilibrium outcomes of the game. The results are then generalized to the game without commitment.

\subsection{Voting on the minimum pension $\left(p^{L}\right)$}

Regardless of the composition of the social security scheme, the elderly are net recipients from the system. Therefore, for any value of $\alpha$, they choose the pension transfer for the low income, $p^{L}$, that maximizes their pension, which is clearly the highest possible, i.e. $p^{L}$ s.t. $\tau=1$.

Today's young individuals may be willing to vote in favor of the pension system, and thus to bear the cost of a current transfer, if their vote will also determine its future size, and thus their future benefits. In the game with commitment, a type- $j$ young individual choose her vote, $p_{j}^{L}$, by maximizing her indirect utility function with respect to a constant sequence of minimum pensions, $p_{t, j}^{L}=p_{t+1, j}^{L}=p_{j}^{L}$. The following proposition summarizes the voting decision of any young individual.

\footnotetext{
${ }^{11}$ We leave the detailed specification of the voting game without commitment to the Appendix.
} 
Proposition 4.1. i) If

$$
\left(1+r^{j}\right) \leq(1+n)\left(\alpha+(1-\alpha) \frac{\bar{w}}{w^{j}}\right)
$$

a young type-j prefers to use only the social security technology to transfer resources to the future (and thus chooses not to save, $s_{t}^{j}=0$ ), and he votes for the following level of pension for the low-income individuals:

$$
p_{j}^{L}(\alpha)=\frac{w^{j}\left(\alpha w^{L}+(1-\alpha) \bar{w}\right)}{\frac{w^{j}}{(1+n)}+\left(\alpha w^{j}+(1-\alpha) \bar{w}\right)^{1-\frac{1}{\gamma}}\left(\frac{w^{j}}{(1+n) \beta}\right)^{\frac{1}{\gamma}}}
$$

ii) If

$$
\left(1+r^{j}\right)>(1+n)\left(\alpha+(1-\alpha) \frac{\bar{w}}{w^{j}}\right)
$$

a young type-j prefers to use only the private saving technology to transfer resources to the future $\left(s_{t}^{j}>0\right)$ and he votes for $p_{j}^{L}(\alpha)=0$.

The intuition of the previous result is the following: if the rate of return of his saving technology, $\left(1+r^{j}\right)$, is higher that the rate of return of the social security system in place, $(1+n)\left(\alpha+(1-\alpha) \bar{w} / w^{j}\right)$, a type- $j$ worker would prefer to transfer resources to the future using the private saving technology rather than the social security system. Thus, in this case he will prefer a zero minimum pension and positive savings. Otherwise, he will choose a positive minimum pension and no private savings.

Notice that the young individual's vote depends on the structure of the social security system: i) if the system is purely Bismarckian $(\alpha=1)$, then a young individual type- $j$ votes for a positive minimum pension if $r^{j} \leq n$; and ii) if the system is purely Beveridgean $(\alpha=0)$ then a young individual type- $j$ votes for a positive minimum pension if $w^{j}(1+r)<\bar{w}(1+n)$.

$>$ From the previous proposition it follows that low-income individuals always prefer the social security system to transfer resources to the future, since we have assumed that their rate of return from private saving is lower than the return from the PAYG system $\left(r^{L}<n\right)$ and $w^{L}<\bar{w}$. Hence, condition 4.1 is satisfied 
and low income individuals vote for a positive level of pension for themselves, according to equation 4.2. On the other hand, high-income individuals always prefer the private saving technology to transfer resources to the future (condition 4.3 is always satisfied, since $r^{H} \geq n$ and $w^{H}>\bar{w}$ ) and they vote for zero minimum pension. The voting behavior of the middle group is instead ambiguous, since it depends on the degree of redistribution $(\alpha)$ and on the performance of the social security system relative to those of the assets that they may access on the capital market $\left(r^{M}\right.$ versus $\left.n\right)$.

The result of the next corollary is crucial to obtain an ordering of the votes over $p^{L}$.

Corollary 4.2. If $\left(1+r^{j}\right) \leq(1+n)\left(\alpha+(1-\alpha)\left(\bar{w} / w^{j}\right)\right)$ (i.e., $\left.s_{t}^{j}=0\right)$, then $d p_{j}^{L} / d w^{j} \geq 0$.

This corollary points out that if an individual prefers to use the social security system as a saving device, the higher is his wage, the higher is his most preferred minimum pension. The intuition is straightforward: richer individuals want to move more resources into the future and therefore, since they use the social security system as their only saving technology, they prefer higher pensions than lower income agents ${ }^{12}$. This corollary thus implies that if the type- $M$ individuals are willing to join the low-income individuals in supporting the social security system, they vote for higher pension than the low type young.

The following proposition identifies the median voter in the jurisdiction $p^{L}$ for a given level of $\alpha$.

Proposition 4.3. The median voter over the jurisdiction $p^{L}$ is:

i) $\operatorname{For}\left(1+r^{M}\right) \leq(1+n)\left(\alpha+(1-\alpha) \bar{w} / w^{M}\right)$

$$
\begin{aligned}
\text { a low type young if } \rho^{H}+\rho^{L} & \geq(2+n) / 2(1+n) \\
\text { a middle type young if } \rho^{H}+\rho^{L} & <(2+n) / 2(1+n)
\end{aligned}
$$

\footnotetext{
${ }^{12}$ This result was already in Casamatta et al (1998).
} 
ii) For $\left(1+r^{M}\right)>(1+n)\left(\alpha+(1-\alpha) \bar{w} / w^{M}\right)$

$$
\begin{aligned}
\text { a low type young if } \rho^{L} & \geq n / 2(1+n) \\
\text { a middle type young if } \rho^{L} & <n / 2(1+n)
\end{aligned}
$$

This proposition suggests that, when the middle income individuals prefer social security as a saving device (case i), their private returns being "low" (see condition 4.1) their most preferred level of $p^{L}$ is larger than the one chosen by the low-income individuals, but lower than the elderly's. Thus, the median voter over $p^{L}$ belongs to the low income type if there are enough high and low-income type and to the middle type otherwise. If instead the middle individuals prefers the private technology as a saving device (case ii), the identity of the median voter depends on the size of the low-income group, because in this case the middle individuals join the high in choosing a level of minimum pension equal to zero. Therefore we have two scenarios. When the median voter is a low type, $p^{L}$ is positive and the middle and high type complement the resources they transfer to the future through private savings; and when the median voter is a middle type, there are no pensions and all resource transfers to the future occurr through private savings.

\subsection{Voting on the Bismarckian factor}

The old have again a simple choice. Since they are no longer required to contribute to the system, they vote for the Bismarckian factor that maximizes their current transfer for a given level of $p^{L}$. Clearly, low type old are indifferent on this dimension, because their final pension, $p^{L}$, is fixed. Middle and high income old vote for $\alpha=1$ (a purely bismarckian system), since, for a given minimum pension, a Bismarckian system maximizes their pension transfers:

$$
\frac{d p^{j}}{d \alpha}=\frac{\bar{w}\left(w^{j}-w^{L}\right)}{\left(\alpha w^{L}+(1-\alpha) \bar{w}\right)^{2}} p^{L}>0 ; j=M, H
$$

We now turn to the young. Because of the assumption of commitment over the social security policies, the voting decision of an ability type $j$ young individual 
amounts to maximizing her indirect utility (eq. 3.8) with respect to current and future bismarckian factors, $\alpha_{t}=\alpha_{t+1}=\alpha$, for a given value of current and future minimum pensions, $p_{t}^{L}=p_{t+1}^{L}=p^{L}$. To appreciate the voting behavior of the young, notice that, for a given value of $p^{L}$, an increase in the Bismarckian factor has a double effect: it raises the pensions to the middle and high types (see equation 3.7), and hence it increases the tax rate to finance the additional pension transfers (see equation 3.6). The next proposition provides a characterization of this voting behavior.

Proposition 4.4. A low-type individual chooses a purely Beveridgean system ( $\alpha=0)$. A type- $j$ individual, with $j=M, H$, vote for $\alpha=0$ if $\left(1+r^{j}\right) \geq$ $(1+n) \frac{\bar{w}}{w^{j}} \frac{\left(w^{j}-w^{L}\right)}{\left(\bar{w}-w^{L}\right)}$ and for $\alpha=1$ if $\left(1+r^{j}\right)<(1+n) \frac{\bar{w}}{w^{j}} \frac{\left(w^{j}-w^{L}\right)}{\left(\bar{w}-w^{L}\right)}$ and $\beta\left(1+r^{j}\right)>$ $\left(\frac{p_{t+1}^{j}}{w_{t}^{j}\left(1-\tau_{t}\right)}\right)^{\gamma}$ (i.e., $\left.s^{j} \geq 0\right)$.

Low types clearly prefer a Beveridgean system, which, for a given $p^{L}$, reduces their wage bill.

High income types are net contributors in a Beveridgean system that redistributes within cohorts. Nevertheless, they are willing to sustain a Beveridgean system $(\alpha=0)$ if the return on their private assets is sufficiently high. The intuition is straightforward: a Beveridgean system reduces their pension transfer, but also their contributions, which may more conveniently be invested in a private asset. This represents a crucial insight of the model, and suggests that alternative saving opportunities may be relevant in shaping the individual preferences over the social security system. If, on the other hand, the return on private asset is not high enough, high income savers choose a Bismarckian scheme ${ }^{13}$.

Middle-types' voting behavior resambles the high types' if their wage exceeds the average wage $\left(w^{M}>\bar{w}\right)$, despite the fact that they enjoy a lower private

\footnotetext{
${ }^{13}$ High type non-savers wish to transfer resources into the present. Thus, even for low private returns, they may be willing to support a Beveridgean scheme in order to decrease today's contributions, and hence to increase today's net income.
} 
return, $r^{M}<r^{H}$. On the other hand, for $w^{M}<\bar{w}$, (and $r^{M} \geq n$ ), the middle types always prefer a Beveridgean system, from which they are net recipients.

It is worth noticing that, as long as the old do not constitute a majority of voters, the maximum level of low type pension that may be voted, $p_{M}^{L}$ (see equation 4.2 and corollary 4.2), is consistent with the middle (and high) type having non negative savings. Thus, the conditions in the previous proposition completely characterize the voting behavior of the middle (and high) type over $\alpha$, for any possible $p^{L *}$.

In what follows, we concentrate on the case of high private returns for the high types. In other words, we assume that $\left(1+r^{H}\right) \geq(1+n) \frac{\bar{w}}{w^{H}} \frac{\left(w^{H}-w^{L}\right)}{\left(\bar{w}-w^{L}\right)}$, and thus high type young support a Beveridgean system. The alternative case is analyzed in the appendix A.6.

Using the results in the previous proposition, the median voter in the jurisdiction $\alpha$ for a given level of $p^{L}$ is:

- a young individual, and $\alpha=0$,

if $\left(1+r^{M}\right) \geq(1+n) \bar{w}\left(w^{M}-w^{L}\right) / w^{M}\left(\bar{w}-w^{L}\right)$

- a high or low-type young and $\alpha=0$,

if $\left(\rho^{H}+\rho^{L}\right)(1+n)+\rho^{L} / 2 \geq(2+n) / 2$

- a middle type young who votes $\alpha=1$,

if $\left(1+r^{M}\right)<(1+n) \bar{w}\left(w^{M}-w^{L}\right) / w^{M}\left(\bar{w}-w^{L}\right)$ and $\left(\rho^{H}+\rho^{L}\right)(1+n)+$ $\rho^{L} / 2<(2+n) / 2$

Under the assumption that high types young obtain sufficiently high returns on private assets, a Beveridgean system is always supported by a coalition of the extreme: low and high types young. Thus, if they constitute a voting majority or if they are joined by the middle-type young, a Beveridgean system arises. If, on the other hand, they do not constitute a majority, and the middle type young oppose a Beveridgean system, a Bismarckian system arises. 


\subsection{The Political Economy Equilibrium}

The previous sections have separately analyzed the voting behavior of all individuals along the two dimensions of the issue space, i.e., the minimum pension and the bismarckian factor, under the assumption of commitment. Since preferences are single peaked, we can now apply Shepsle's (1979) result, and characterize the structure induced equilibria of the game with commitment. The next proposition characterizes the politico-economic equilibrium outcomes of our voting game.

Proposition 4.5. There exists a structure induced equilibrium, $\left(p^{L *}, \alpha^{*}\right)$, of the voting game with commitment, such that:

A. If $w^{M}<\bar{w}$ :

i) If $\left(1+r^{M}\right) \leq(1+n) \bar{w} / w^{M}$

$$
\begin{aligned}
& \left(p^{L *}=p_{L}^{L}(0), \alpha^{*}=0\right) \quad \text { if } \quad\left(\rho^{H}+\rho^{L}\right) \geq \frac{(2+n)}{2(1+n)} \\
& \left(p^{L *}=p_{L}^{M}(0), \alpha^{*}=0\right) \quad \text { otherwise }
\end{aligned}
$$

ii) If $\left(1+r^{M}\right)>(1+n) \bar{w} / w^{M}$

$$
\begin{array}{cll}
\left(p^{L *}=p_{L}^{L}(0), \alpha^{*}=0\right) & \text { if } & \rho^{L} \geq \frac{n}{2(1+n)} \\
\left(p^{L *}=p_{L}^{M}(0)=0, \alpha^{*}=0\right) & & \text { otherwise }
\end{array}
$$

B. If $w^{M} \geq \bar{w}$

i) If $\left(1+r^{M}\right) \leq(1+n) \bar{w}\left(w^{M}-w^{L}\right) / w^{M}\left(\bar{w}-w^{L}\right)$

$$
\begin{aligned}
& \left(p^{L *}=p_{L}^{L}(1), \alpha^{*}=1\right) \quad \text { if }\left\{\begin{array}{c}
\left(\rho^{H}+\rho^{L}\right)+\frac{\rho^{L}}{2(1+n)}<\frac{(2+n)}{2(1+n)} \\
\rho^{L} \geq \frac{n}{2(1+n)}
\end{array}\right. \\
& \left(p^{L *}=p_{L}^{L}(0), \alpha^{*}=0\right) \quad \text { if }\left\{\begin{array}{c}
\left(\rho^{H}+\rho^{L}\right)+\frac{\rho^{L}}{2(1+n)} \geq \frac{(2+n)}{2(1+n)} \\
\rho^{L} \geq \frac{n}{2(1+n)}
\end{array}\right. \\
& \left(p^{L *}=p_{M}^{L}(0)=0, \alpha^{*}=0\right) \text { if }\left\{\begin{array}{c}
\left(\rho^{H}+\rho^{L}\right)+\frac{\rho^{L}}{2(1+n)}<\frac{(2+n)}{2(1+n)} \\
\rho^{L}<\frac{n}{2(1+n)}
\end{array}\right.
\end{aligned}
$$




$$
\begin{aligned}
& \text { ii) If }\left(1+r^{M}\right)>(1+n) \bar{w}\left(w^{M}-w^{L}\right) / w^{M}\left(\bar{w}-w^{L}\right) \\
& \left(p^{L *}=p_{L}^{L}(0), \alpha^{*}=0\right) \quad \text { if } \quad \rho^{L} \geq \frac{n}{2(1+n)} \\
& \left(p^{L *}=p_{M}^{L}(0)=0, \alpha^{*}=0\right) \quad \text { otherwise }
\end{aligned}
$$

The proposition shows that a Beveridgean system will always arise when the middle group has a wage lower than the average wage. However, the interesting result is that even when $w^{M} \geq \bar{w}$, a Beveridgean system will be an equilibrium as long as both high and middle income groups have sufficiently high returns from private savings (larger than the threshold $(1+n) \bar{w}\left(w^{j}-w^{L}\right) / w^{j}\left(\bar{w}-w^{L}\right), j=$ $M, H)$. If middle income individuals do not enjoy a high return from private savings, but high income individuals do (case B i), a Beveridgean system will still arise if there are enough low and high types. We interpret this condition as the characterization of an economy with large inequality. On the other side, a Bismarckian system arises when there exists a large share of middle types, which we may interpret as a condition that characterizes an economy with low inequality. In other words, when $w^{M} \geq \bar{w}$ and middle income individuals do not enjoy a high return from private savings, but high income individuals do (case B i), aggregating preferences, one equilibrium of the voting game arises: if income inequality is large, high income groups join the low income people in a voting majority that supports a Beveridgean system; if income inequality is small, middle income people represents a majority which sustains a Bismarckian system. This result delivers a testable prediction: Beveridgean systems are associated with larger inequality than Bismarckian ones.

Additional results arise when we focus on the capital market. Interestingly, the equilibrium system may be Bismarckian only if the interest rate for the middle income is lower than the threshold $(1+n) \bar{w}\left(w^{M}-w^{L}\right) / w^{M}\left(\bar{w}-w^{L}\right)$, while if the interest rate of the middle income is higher than this threshold, the system is Beveridgean. In other words, when the capital market is more efficient and provides higher returns, it is more likely to have a Beveridgean system. This result delivers an additional testable prediction: a PAYG Beveridgean system is 
associated with a larger private pillar, which yields higher returns.

The next Corollary delivers an additional empirical predictions and finally explains the "puzzle".

Corollary 4.6. $p_{L}^{L}(0) \geq p_{L}^{L}(1)$ and $\tau(0) \leq \tau(1)$

Corollary 4.6 shows that a Beveridgean system is associated with a higher pension for the low-income individuals and a lower size of the PAYG system (a lower tax rate) than a Bismarckian. The last result resolves the "puzzle", i.e., our bidimensional political economy model of social security explains the association between a higher Bismarckian factor and a higher level of PAYG social security expenditures.

Finally, what happens if we relax the assumption of commitment and consider a game in which voters may only determine the current bismarckian factor and minimum pension? The next proposition shows that the results in proposition 4.5 may be generalized to a game without commitment:

Proposition 4.7. Every pair $\left(p^{L *}, \alpha^{*}\right)$, which constitutes a (structure induced) equilibrium of the voting game with commitment, is a (subgame perfect structure induced) equilibrium of the game without commitment.

Proposition 4.7 suggests that there exists a system of punishment and rewards, which makes the equilibrium outcome of the game with commitment a subgame perfect equilibrium outcome of the game without commitment. The intuition is straightforward. Old agents' voting behavior does not depend on tomorrow's policy and thus on the existence of commitment. Young individuals, who were in favor of a positive social security system (either Beveridgean or Bismarkian) in case of commitment, will now be willing to enter an "implicit contract" among successive generations of voters to sustain the welfare state. This "implicit contract" specifies that, if current young support the existing welfare system, they will be rewarded with a corresponding transfer of resources in their old age, or they will be punished, and receive no transfers. 


\section{Testing the Empirical Predictions}

In this section we aim at testing the following empirical predictions, implied by the model:

1. The more "Bismarckian" a system is, the lower is the pension of the low income people

2. The more "Bismarckian" a system is, the lower is the income inequality in the country

3. The more "Bismarckian" a system is, the lower is the private pension pillar.

Table 3 shows that according to our calculations on the ECHP data, countries with a higher Beveridgean index are associated with a higher replacement rate for low-income individuals, both calculated as the replacement rate of the bottom $33 \%$ and the bottom $20 \%$. We interpret this as evidence that more Beveridgean systems offer a higher pension to low income individuals, as suggested by our model. ${ }^{14}$

Table 4 reports measures of inequality from the World Development Indicators, World Bank 2000. The table shows that the Gini index is significantly higher in the UK (36.1) than in Italy (27.3) or France (32.7). This is due to a higher concentration of income in the highest $20 \%$ in the UK, while the "middle" class (second, third and fourth $20 \%$ of the distribution) is significantly larger in Italy (55) and France (52.6) than in the UK (50.4). These results confirm our second prediction.

Table 5 reports measures of the extension of the second pillar in the European countries according to the data reported by the Green Paper of the European Commission 1997, based on the European federation for Retirement Provision 1996. The differences are very large: in the UK pension funds assets represent the $79.4 \%$ of the GDP and in the Netherlands the $88.5 \%$, while in France they only absorb the $3.4 \%$ of the GDP and in Italy an even smaller amount (1.2\%).

\footnotetext{
${ }^{14}$ Notice that in our model the higher is the minimum pension, the higher is the replacement rate of the low-type individual.
} 
Supplementary pensions represent the $28 \%$ of the total pension in the UK, and only the $2 \%$ in Italy. These data are consistent with our third prediction, that the second pillar is much more developed in Beveridgean countries, where the public pillar is smaller, than in Bismarckian countries, where the public pension offers very large amounts.

Table 5 also shows that the financial markets have a relevant role in the type of system: in the UK the average nominal rate of return from pension funds is 15.5, which is the highest value for the available countries, and market capitalization is $149.9 \%$ of GDP, while in France it is $38.9 \%$ and in Italy only $21.7 \%$. These results confirm that when the rate of returns of private pensions is higher, a Beveridgean system is more likely to emerge.

\section{Conclusions}

This paper extends previous contributions by Casamatta, Cremer and Pestieau (1998) and Pestieau (1999) aimed at explaining the following "puzzle": why are Beveridgean social security systems larger than Bismarckian ones, though they can enjoy larger support by low-income individuals due to their redistributive characteristic?

We collect data from the European Commission Household Panel (4 waves) which confirm that more Bismarckian systems are associated with larger pension expenditures. Also, the data show that Beveridgean systems are characterized by a very high level of the replacement rate of the lowest income people. This feature motivates our model, which aims at jointly determining the level of the minimum pension and the degree of redistribution of the pension formula (the Bismarckian factor) in a bidimensional political economy approach. Other features that differentiate Bismarckian and Beveridgean systems are explained by the model: Bismarckian systems tend to be associated with lower inequality and with a lower size of the private pillar. The explanation is very intuitive: in an economy with three income groups, low-income people support a large, redistributive system; 
middle-income favor an earning-related system, while high-income people oppose any public system, since they have access to a superior saving technology, e.g. a private system. If income inequality is large, high and low-income people form a voting majority which supports a (small) Beveridgean system, and a large private pillar may arise; if income inequality is small, middle-income and elderly people represent a majority which sustains a (large) Bismarckian system and the private pillar turns out to be small. Additionally, we show that when capital market is more efficient and provides higher returns, it is more likely to have a Beveridgean system.

The analysis could be extended in several ways. First, using our theoretical framework, one may ask how reforms in the degree of redistributiveness of the public PAYG system may affect the development of the private pension schemes. As a policy implication, the results of the model suggest that in order to reduce their public pension expenditures, Bismarckian countries should encourage the development of the second pillar. However, we showed that this outcome is associated with a more redistributive system, which guarantees higher replacement rates to lower income individuals. We thus expect that recent reforms, like the Italian reform of 1995, introducing the (notional) defined contribution method, and thus a closer link between contributions and benefits, and no redistribution, would imply a system where the role of the second pillar remains marginal. Second, the data collected in this analysis and the predictions of the model suggest that the pension systems in European countries differ in many aspects. What role will current policies, such as the harmonization of the pension systems in a European context, have on the differences between european pension systems? Do we expect european countries to react differently to current common trends, such as the aging process? These questions suggest directions for future research. 


\section{A. Appendix}

\section{A.1. The Voting Game and the Notion of Equilibrium}

In this appendix, we define the voting game and formalize our concept of equilibrium: the stationary subgame perfect structure induced equilibrium. We consider that voters may only determine the current minimum pension and the current Bismarckian factor, although they may expect their vote to condition future voters' decisions. We define the voting game with no commitment as follows.

The public history of the game at time $t, h_{t}=\left\{\left(p_{0}^{L}, \alpha_{0}\right), \ldots,\left(p_{t-1}^{L}, \alpha_{t-1}\right)\right\} \in$ $H_{t}$, is the sequence of social security minimum pensions and Bismarckian factor parameters until $t-1$, where $H_{t}$ is the set of all possible history at time $t$. An action for a type $j$ young individual at time $t$ is a pair of social security minimum pension and Bismarckian factor parameter, $a_{t, j}^{y}=\left(p^{L}, \alpha\right) \in[0,1] \times[0,1]$, where $j=\{L, M, H\}$. Analogously, an action for a type $j$ old individual at time $t$ is $a_{t, j}^{o}=\left(p^{L}, \alpha\right) \in[0,1] \times[0,1]$. Thus, at time $t$ every voter chooses a pair $\left(p^{L}, \alpha\right)$. We identify with $a_{t}$ the action profile of all individuals (young and old) at time $t$ : $a_{t}=\left(a_{t}^{y} \cup a_{t}^{o}\right)$ where $a_{t}^{y}=a_{t, L}^{y}, a_{t, M}^{y}, a_{t, H}^{y}$ and $a_{t}^{o}=a_{t, L}^{o} \cup a_{t, M}^{o} \cup a_{t, H}^{o}$.

A strategy for a type $j$ young individual at time $t$ is a mapping from the history of the game into the action space: $\sigma_{t, j}^{y}: h_{t} \rightarrow[0,1] \times[0,1]$. Analogously, a strategy for a type $j$ old individual at time $t$ is $\sigma_{t, j}^{o}: h_{t} \rightarrow[0,1] \times[0,1]$. We denote with $\sigma_{t}$ the strategy profile played by all individuals at time $t$, i.e., $\sigma_{t}=\left(\sigma_{t}^{y} \cup \sigma_{t}^{o}\right)$ where $\sigma_{t}^{y}=\left(\sigma_{t, L}^{y}, \sigma_{t, M}^{y}, \sigma_{t, H}^{y}\right)$ and $\sigma_{t}^{o}=\left(\sigma_{t, L}^{o}, \sigma_{t, M}^{o}, \sigma_{t, H}^{o}\right)$.

For a given action profile at time $t, a_{t}$, let $\left(p_{t}^{L, m}, \alpha_{t}^{m}\right)$ be respectively the median of the distribution of tax rates, and the median of the distribution of the Bismarckian parameters. We call $\left(p_{t}^{L, m}, \alpha_{t}^{m}\right)$ the outcome function of the voting game at time $t$. Notice that this outcome function corresponds to the structure induced equilibrium outcome of a voting game at time $t$ in which agents can commit to the future policy.

The history of the game is updated according to the outcome function; at time $t+1: h_{t+1}=\left\{\left(p_{0}^{L}, \alpha_{0}\right), \ldots,\left(p_{t-1}^{L}, \alpha_{t-1}\right),\left(p_{t}^{L, m}, \alpha_{t}^{m}\right)\right\} \in H_{t+1}$. 
For a given sequence of action profiles, $\left(a_{0}, \ldots, a_{t}, a_{t+1}, \ldots\right)$, and their corresponding realizations, $\left(\left(p_{0}^{L}, \alpha_{0}\right), \ldots,\left(p_{t}^{L}, \alpha_{t}\right),\left(p_{t+1}^{L}, \alpha_{t+1}\right), \ldots\right)$, the expected payoff function for a type $j$ young individual at time $t$ is $v_{t}^{y, j}\left(p_{t}^{L}, \alpha_{t}, p_{t+1}^{L}, \alpha_{t+1}\right)$ and for a type $j$ old agent is $v_{t}^{o, j}\left(p_{t}^{L}, \alpha_{t}\right)$, according to equation 3.9 ..

Let $\sigma_{t \mid \widehat{j}}^{y}=\sigma_{t}^{y} / \sigma_{t, \hat{j}}^{y}$ be the strategy profile at time $t$ for all the young individuals except for the type $\widehat{j}$ young individual, and let $\sigma_{t \mid \widehat{j}}^{o}=\sigma_{t}^{o} / \sigma_{t, \hat{j}}^{o}$ be the strategy profile at time $t$ for all the old individuals except for the type $\widehat{j}$ old individual. At time $t$, the type $\widehat{j}$ young individual maximizes the following function:

$$
V_{t}^{y, \widehat{j}}\left(\sigma_{o}, \ldots,\left(\sigma_{t \mid \widehat{j}}^{y}, \sigma_{t, \widehat{j}}^{y}\right), \sigma_{t}^{o}, \sigma_{t+1}, \ldots\right)=v_{t}^{y, \widehat{j}}\left(p_{t}^{L, m}, \alpha_{t}^{m}, p_{t+1}^{L, m}, \alpha_{t+1}^{m}\right)
$$

and a type $\hat{j}$ old individual, at time $t$, maximizes the following function

$$
V_{t}^{o, \widehat{j}}\left(\sigma_{o}, \ldots,\left(\sigma_{t \mid \widehat{j}}^{o}, \sigma_{t, \widehat{j}}^{o}\right), \sigma_{t}^{y}, \sigma_{t+1}, \ldots\right)=v_{t}^{o, \widehat{j}}\left(p_{t}^{L, m}, \alpha_{t}^{m}\right)
$$

where, according to our previous definition of the outcome function, $\left(p_{t}^{L, m}, \alpha_{t}^{m}\right)$ and $\left(p_{t+1}^{L, m}, \alpha_{t+1}^{m}\right)$ are, respectively, the median among the actions over the two parameters of the social security system played at time $t$ and $t+1$.

We can now define a stationary subgame perfect structure induced equilibrium of the voting game as follows:

Definition A.1 (SSPSIE). A stationary voting strategy profile $\sigma=\left\{\left(\sigma_{t}^{y} \cup \sigma_{t}^{o}\right)\right\}_{t=0}^{\infty}$ is a Stationary Subgame Perfect Structure Induced Equilibrium (SSPSIE) if the following conditions are satisfied:

(i) $\sigma$ is a subgame perfect equilibrium.

(ii) At every time $t$, the equilibrium outcome associated to $\sigma$ is a Structure Induced Equilibrium of the static game with commitment over future policy.

\section{A.2. Proof of Proposition 4.1}

A worker type- $j$ chooses a level of $p_{j}^{L}$ which maximizes his indirect utility function $v_{t}^{t, j}\left(p_{t}^{L}, \alpha_{t}, p_{t+1}^{L}, \alpha_{t+1}\right)$ as described at equation 3.8. The first order condition of 
the previous indirect utility function with respect to $p_{t+1}^{L}=p_{t}^{L}=p^{L}$ for a given $\alpha_{t}=\alpha_{t+1}=\alpha$ is:

$$
-\frac{w_{t}^{j}}{(1+n)}+\frac{\left(\alpha w^{j}+(1-\alpha) \bar{w}\right)}{1+r^{j}}
$$

Therefore, an individual will be in favor of a zero minimum pension if the above condition is negative, i.e. if $1+r^{j}>(1+n)\left(\alpha+(1-\alpha) \bar{w} / w_{t}^{j}\right)$, which corresponds to condition 4.3. On the contrary, he will choose a positive level of the minimum pension if $1+r^{j} \leq(1+n)\left(\alpha+(1-\alpha) \bar{w} / w_{t}^{j}\right)$, which corresponds to equation 4.1.

If condition 4.3 holds, the implicit rate of return from private savings is higher than the return from PAYG Social Security, while if condition 4.1 holds, the implicit rate of return from private savings is lower than the return from PAYG Social Security. Since savings are forced to be non negative, an individual who, according to equation 4.3, chooses a zero pension for the low-income group (which implies a zero pension for any group) also chooses a positive level of savings, while an individual who, according to equation 4.1 chooses a positive level of pension for the low income group, has zero savings. In this last case, the individual prefers to use the social security system to transfer resources to the future rather than the private savings, and vote for the level of the minimum pension such that $s_{t}^{j *}=0$. From equation 3.3, it is easy to show that

$$
p_{j}^{L}=\frac{w^{j}\left(\alpha w^{L}+(1-\alpha) \bar{w}\right)}{\frac{w^{j}}{(1+n)}+\left(\alpha w^{j}+(1-\alpha) \bar{w}\right)^{1-\frac{1}{\gamma}}\left(\frac{w^{j}}{(1+n) \beta}\right)^{\frac{1}{\gamma}}}
$$

\section{A.3. Proof of Corollary 4.2.}

Just notice that the following expression is positive if $\gamma>1$

$$
\frac{d p_{j}^{L}}{d w^{j}}=\left(1-\frac{1}{\gamma}\right) \frac{\left(\alpha w^{L}+(1-\alpha) \bar{w}\right)\left(\frac{w^{j}}{(1+n) \beta}\right)^{\frac{1}{\gamma}}\left(\alpha w^{j}+(1-\alpha) \bar{w}\right)^{-\frac{1}{\gamma}}(1-\alpha) \bar{w}}{\left[\frac{w^{j}}{(1+n)}+\left(\alpha w^{j}+(1-\alpha) \bar{w}\right)^{1-\frac{1}{\gamma}}\left(\frac{w^{j}}{(1+n) \beta}\right)^{\frac{1}{\gamma}}\right]^{2}}
$$




\section{A.4. Proof of Proposition 4.3}

i) If condition 4.1 is satisfied for $j=M$, i.e. $\left(1+r^{M}\right) \leq(1+n)\left(\alpha+(1-\alpha) \frac{\bar{w}}{w^{M}}\right)$ then $p_{M}^{L}>0$. By corollary 4.2, $p_{M}^{L}>p_{L}^{L}>0$ and we know that $p_{H}^{L}=0$. The high type and the low type young prefer a lower minimum pension than the old and the middle type young. In this case if the low and the high types young constitute a majority in the total population the median voter will be a low type young, otherwise the median voter will be a middle type young.

ii) If $\left(1+r^{M}\right)>(1+n)\left(\alpha+(1-\alpha) \frac{\bar{w}}{w^{M}}\right)$, then $p_{L}^{L}>p_{M}^{L}=p_{H}^{L}=0$, that is the high type and the middle type young prefer a lower minimum pension than the old and the low type young. In this case if the middle and the high types young constitute a majority in the total population, the median voter will be a middle type young, otherwise the median voter will be a low type young.

\section{A.5. Proof of Proposition 4.4.}

First notice that, for a given $p^{L}$, an increase in $\alpha$ increases the tax rate (from equation 3.6):

$$
\frac{\partial \tau}{\partial \alpha}=-\frac{\tau\left(w^{L}-\bar{w}\right)}{\alpha w^{L}+(1-\alpha) \bar{w}}>0
$$

and increases the middle and high type's pensions (from equations 3.7):

$$
\frac{\partial p^{j}}{\partial \alpha}=\frac{\bar{w}\left(w^{j}-w^{L}\right) p^{L}}{\left(\alpha w^{L}+(1-\alpha) w^{H}\right)^{2}}>0 \text { for } j=M, H
$$

Thus, the effect on the indirect utility function of a low type (see equation 3.8 ) of an increase in $\alpha$ is always negative (for a given $p^{L}$ ) and hence they vote for $\alpha=0$.

For low and high type savers, $s^{*, j}>0$, by the envelop theorem, we can concentrate on the effect on the lifetime income (indicated by $I^{j}$ ):

$$
\frac{\partial I^{j}}{\partial \alpha}=\frac{p^{L}}{\left(\alpha w^{L}+(1-\alpha) w^{H}\right)^{2}}\left(-\frac{w^{j}\left(\bar{w}-w^{L}\right)}{1+n}+\frac{\bar{w}\left(w^{j}-w^{L}\right)}{1+r^{j}}\right)
$$

It is easy to see that $\frac{\partial I^{j}}{\partial \alpha}$ is negative, and hence $\alpha^{j}=0$, for $\left(1+r^{j}\right) \geq$ $(1+n) \frac{\bar{w}}{w^{j}} \frac{\left(w^{j}-w^{L}\right)}{\left(\bar{w}-w^{L}\right)}$, otherwise $\alpha=1$. Notice that for $w^{M}<\bar{w}$ the ratio on the 
RHS of the previous inequality is less than one, and thus the inequality is always satisfied, since $r^{M} \geq n$. This implies that for $w^{M}<\bar{w}, \alpha^{M}=0$.

Non-savers are at a corner solution in their saving decision, and thus the envelop theorem does not apply. In particular, they would like to borrow against future pension wealth to transfer resources into the present. Analytically,

$$
-\frac{\partial U}{\partial c_{t}^{t}}+\beta \frac{\partial U}{\partial c_{t+1}^{t}}<0
$$

For middle and high type non-savers, the choice of $\alpha$ amounts to maximize the following expression: $U\left(w^{j}(1-\tau)\right)+\beta U\left(p^{j}\right)$. Thus, we have:

$$
\frac{p^{L}}{\left(\alpha w^{L}+(1-\alpha) \bar{w}\right)^{2}}\left(-\frac{\partial U}{\partial c_{t}^{t}} \frac{w^{j}\left(\bar{w}-w^{L}\right)}{1+n}+\beta \frac{\partial U}{\partial c_{t+1}^{t}} \frac{\bar{w}\left(w^{j}-w^{L}\right)}{1+r^{j}}\right)
$$

Using A.1, it is easy to see that the previous FOC is always negative, and hence $\alpha^{j}=0$, if $\left(1+r^{j}\right) \geq(1+n) \frac{\bar{w}}{w^{j}} \frac{\left(w^{j}-w^{L}\right)}{\left(\bar{w}-w^{L}\right)}$. However, now reversing the previous inequality does not imply that $\alpha^{j}=1$. Therefore, in the proposition we characterize the condition for middle and high types to vote $\alpha=1$ for savers only, i.e., when $\beta\left(1+r^{j}\right)>\left(\frac{p_{t+1}^{j}}{w_{t}^{j}\left(1-\tau_{t}\right)}\right)^{\gamma}$.

A.6. Case $\left(1+r^{H}\right)<(1+n) \frac{\bar{w}}{w^{H}} \frac{\left(w^{H}-w^{L}\right)}{\left(\bar{w}-w^{L}\right)}$

In this case, the median voter over $\alpha$ is:

- a middle or high type young, and $\alpha=1$, if $\left(1+r^{M}\right)<(1+n) \bar{w}\left(w^{M}-w^{L}\right) /$ $w^{M}\left(\bar{w}-w^{L}\right)$

- a high type young, and $\alpha=1$, if $\frac{1-\rho^{L}}{2}+(1+n) \rho^{H}>\frac{1+n}{2}$

- a middle type young, and $\alpha=0$, if $\left(1+r^{M}\right)>(1+n) \bar{w}\left(w^{M}-w^{L}\right) /$ $w^{M}\left(\bar{w}-w^{L}\right)$ and $\left(\rho^{H}+\rho^{L}\right)(1+n)+\frac{\rho^{L}}{2} \geq \frac{(2+n)}{2}$ 


\section{A.7. Proof of Proposition 4.5}

Notice that since $\left(1+r^{H}\right) \geq(1+n) \bar{w}\left(w^{H}-w^{L}\right) / w^{H}\left(\bar{w}-w^{L}\right)$ and $\left(1+r^{L}\right) \leq$ $(1+n)$, the low type and the high type young vote for a purely beveridgean system, the low type young vote always for a positive minimum pension and the high type young vote for a zero minimum pension. We thus have to characterize the choice of the middle young.

A) For $w^{M}<\bar{w}$ :

The middle young always vote for $\alpha=0$, since $\left(1+r^{M}\right) \geq(1+n) \bar{w}\left(w^{M}-\right.$ $\left.w^{L}\right) / w^{M}\left(\bar{w}-w^{L}\right)$ when $w^{M}<\bar{w}$ and $r^{M} \geq n$. Thus, when $\alpha=0$, if $\left(1+r^{M}\right) \leq$ $(1+n) \bar{w} / w^{M}$ (which is equal to condition 4.1 with $\alpha=0$ ), the middle young vote for $p_{M}^{L}>0$, and if $\left(1+r^{M}\right)>(1+n) \bar{w} / w^{M}$ they vote for $p_{M}^{L}=0$. We thus have 2 cases:

A i) If $\left(1+r^{M}\right) \leq(1+n) \bar{w} / w^{M}$, the middle type young vote for $\alpha=0$ and for a $p_{M}^{L}>p_{L}^{L}>0$. Therefore the system is always purely Beveridgean since all the young vote for $\alpha=0$. The middle type young is the median voter in the minimum pension jurisdiction only if $\left(\rho^{H}+\rho^{L}\right)(1+n)$ does not constitutes a majority, i.e. $\left(\rho^{H}+\rho^{L}\right)(1+n)<(2+n) / 2$ where $2+n$ is the size of the total population.

A ii) If $\left(1+r^{M}\right)>(1+n) \bar{w} / w^{M}$, the middle type young vote for $\alpha=0$ and for a $p_{M}^{L}=0$. Therefore the system is always again purely Beveridgean. The low type young is the median voter in the minimum pension jurisdiction only if the coalition of the old and the low ability constitutes a majority, i.e. $\left(1-\rho^{L}\right)(1+n) \leq(2+n) / 2$ where $\left(1-\rho^{L}\right)(1+n)$ is the size of young low and middle and $2+n$ is the size of the total population .

B) For $w^{M} \geq \bar{w}$ :

The middle young always vote for $p_{M}^{L}=0$, since $(1+n)\left(\alpha+(1-\alpha) \bar{w} / w^{M}\right) \leq$ $1+n$ and $1+r^{M} \geq 1+n$ imply that condition 4.3 is always satisfied for middle young individuals. However,

if $(1+n)<\left(1+r^{M}\right) \leq(1+n) \bar{w}\left(w^{M}-w^{L}\right) / w^{M}\left(\bar{w}-w^{L}\right)$ they vote for $\alpha=1$ and 
if $\left(1+r^{M}\right)>(1+n) \bar{w}\left(w^{M}-w^{L}\right) / w^{M}\left(\bar{w}-w^{L}\right)$ they vote for $\alpha=0$. Thus we have two cases:

$\mathrm{B}$ i) If $(1+n)<\left(1+r^{M}\right) \leq(1+n) \bar{w}\left(w^{M}-w^{L}\right) / w^{M}\left(\bar{w}-w^{L}\right)$ the middle type young always vote for a purely Bismarckian system $\alpha=1$ and for zero minimum pension. The system is Beveridgean if the low and the high young are the majority of the population, i.e. $\left(\rho^{H}+\rho^{L}\right)(1+n)>\left(2+n-\rho^{L}\right) / 2$, where $2+n-\rho^{L}$ is the size of total population (remember that the old low are indifferent), which is equaivalent to say that $\left(\rho^{H}+\rho^{L}\right)+\rho^{L} / 2 \geq(2+n) / 2$. The median voter over $p^{L}$ is a low ability young if the coalition of the old and the low ability young constitutes a majority. Otherwise the system is Bismarckian.

$\mathrm{B}$ ii) If $\left(1+r^{M}\right)>(1+n) \bar{w}\left(w^{M}-w^{L}\right) / w^{M}\left(\bar{w}-w^{L}\right)$ the middle type young always vote for a purely Beveridgean system and for zero minimum pension. Therefore the whole young generation vote for a beveridgean system. But the low ability young group is the median voter only if $\rho^{L} \geq n / 2(1+n)$ like in case Aii).

\section{A.8. Proof of Corollary 4.6}

The minimum pension under a purely beveridgean and purely bismarckian system are the following:

$$
\begin{aligned}
& p_{L}^{L}(0)=\frac{w^{L}}{\frac{w^{L}}{\bar{w}(1+n)}+\left(\frac{w^{L}}{\bar{w}(1+n) \beta}\right)^{\frac{1}{\gamma}}} \\
& p_{L}^{L}(1)=\frac{w^{L}}{\frac{1}{(1+n)}+\left(\frac{1}{(1+n) \beta}\right)^{\frac{1}{\gamma}}}
\end{aligned}
$$

and $p_{L}^{L}(0)>p_{L}^{L}(1)$ because $w^{L} / \bar{w}<1$.

The purely beveridgean and purely bismarckian tax rates are the following:

$$
\begin{aligned}
\tau(0) & =\frac{1}{(1+n)\left[\frac{1}{(1+n)}+\left(\frac{\bar{w}}{w^{L}}\right)^{1-\frac{1}{\gamma}}\left(\frac{1}{(1+n) \beta}\right)^{\frac{1}{\gamma}}\right]} \\
\tau(1) & =\frac{1}{(1+n)\left(\frac{1}{(1+n)}+\left(\frac{1}{(1+n) \beta}\right)^{\frac{1}{\gamma}}\right)}
\end{aligned}
$$


where, if $\gamma \geq 1$ then $\tau(0) \leq \tau(1)$.

\section{A.9. Proof of Proposition 4.7}

See Conde-Ruiz and Galasso (2000 and 2002) to show that Structure Induce Equi-

librium outcomes $\left(p^{L *}, \alpha^{*}\right)$ are also subgame perfect equilibrium outcomes of the game described in the appendix A.1. 


\section{References}

[1] Casamatta, G. and Cremer, H. and Pestieau, P. (1998). The Political Economy of Social Security, Scandinavian Journal of Economics.

[2] Conde-Ruiz, J. I. and Galasso, V. (1999) Positive Arithmetic of the Welfare State. CEPR Discussion Paper 2202.

[3] Conde-Ruiz, J. I. and Galasso, V. (2002) Early Retirement, forthcoming in Review of Economic Dynamics.

[4] Cremer, H. and Pestieau, P. (1988). Social Insurance, Majority Voting and Labor Mobility, in Journal of Public Economics.

[5] Disney, R., M. Mira d'Ercole and P. Scherer (1998), "Resources During Retirement", Aging Working Paper 4.3, OECD.

[6] Disney, R. and Johnson, P. ed. (2001) Pension Systems and Retirement Incomes across OECD countries. Edward Elgar editor.

[7] European Commission Household Panel. Wave 1993, 1994, 1995, 1996.

[8] Galasso, V. and Profeta, P. (2002) Political Economy Models of Social Security: A survey, in European Journal of Political Economy 18(1), 1-29.

[9] European Commission. Supplementary Pensions in the Single Market. A Green Paper.

[10] Nicoletti, C. and Peracchi, F. (2002). Aging in Europe: A cross-country comparison. mimeo, University of Essex and University of Rome Tor Vergata.

[11] Nicoletti, C. and Peracchi, F. (2001). Aging in Europe: What can we learn from the Europanel? in T. Boeri, A. Borsch-Supan, A.Brugiavini, R. Disney, A. Kapteyn and F. Peracchi (eds), Pensions: More informations, less Ideology. Assessing the Long Term Sustainability of European Pension Systems: Data requirements, Analysis and Evaluations, Kluwer, Dordrecht. 
[12] Organisation For Economic Co-operation and Development (OECD). Social Expenditure Database: 2nd edition 1980/1997.

[13] Peracchi, F. (2002). The European Community Household Panel: A review, in Empirical Economics, 27, 63-90.

[14] Pestieau, P. The Political Economy of Redistributive Social Security (1999), w.p. International Monetary Fund

[15] Persson, T. and Tabellini, G. (2000) Political Economics. Explaining Economic Policy. MIT Press.

[16] Shepsle, K. (1979). Institutional arrangements and equilibrium in multidimensional voting models. American Journal of Political Science 23: 27-59.

[17] World Bank (2000). World Development Indicators. 
Table 1: Replacement Rates Across Income Groups in European Countries

\begin{tabular}{|c|c|c|c|c|c|c|c|c|c|c|c|c|c|c|}
\hline Country & Germany & Denmark & Netherlands & Belgium & Luxembourg & France & $\begin{array}{c}\text { United } \\
\text { Kingdom }\end{array}$ & Ireland & Italy & Greece & Spain & Portugal & Austria & Finland \\
\hline Low & n.a. & 1,2749 & n.a. & 0,9208 & 3 & 1,0295 & 2,1667 & 0,7084 & 1,0500 & 0,9722 & 1,0707 & 1,2177 & 1,0303 & 1,3495 \\
\hline Middle & n.a. & 0,7378 & n.a. & 0,7914 & 0,9053 & 0,8300 & 0,6140 & 0,6535 & 0,8496 & 0,7938 & 0,8686 & 0,7661 & 0,6603 & 1,0421 \\
\hline High & n.a. & 0,6524 & n.a. & 0,7143 & 0,8205 & 0,7450 & 0,5118 & 0,6043 & 0,7902 & 0,9143 & 0,8491 & 1,0000 & 0,7129 & 1,1766 \\
\hline$(1-\mathrm{M}) / \mathrm{I}$ & $n=$ & 04213 & $n=$ & 01406 & 06982 & 01938 & 07166 & 00775 & 01909 & 01836 & 01887 & 03708 & 03591 & 02278 \\
\hline$(\mathrm{M}-\mathrm{H}) / \mathrm{M}$ & n.a. & $\begin{array}{l}0,4<10 \\
0,1157\end{array}$ & n.a. & 0,0974 & $\begin{array}{l}0,0002 \\
0,0937\end{array}$ & 0,1024 & 0,1664 & 0,0753 & 0,0699 & $\begin{array}{r}0,1000 \\
-0,1519\end{array}$ & \begin{tabular}{|l|}
, 1001 \\
0,0225 \\
\end{tabular} & $-0,3052$ & -0,0796 & $-0,1291$ \\
\hline$(\mathrm{L}-\mathrm{H}) / \mathrm{L}$ & n.a. & 0,4883 & n.a. & 0,2243 & 0,7265 & 0,2763 & 0,7638 & 0,1469 & 0,2475 & 0,0595 & 0,2070 & 0,1788 & 0,3081 & 0,1282 \\
\hline $\begin{array}{l}\text { Beveridgean } \\
\text { index }\end{array}$ & n.a. & 0,3418 & n.a. & 0,1541 & 0,5061 & 0,1908 & 0,5489 & 0,0999 & 0,1694 & 0,0304 & 0,1394 & 0,0814 & 0,1958 & 0,0756 \\
\hline $\mathrm{n}^{\circ}$ obs. Low & & 30 & & 25 & 7 & 64 & 37 & 21 & 112 & 35 & 40 & 50 & 20 & 5 \\
\hline $\mathrm{n}^{\circ}$ obs. Middle & & 30 & & 25 & 8 & 64 & 37 & 21 & 112 & 35 & 40 & 50 & 20 & 5 \\
\hline $\mathrm{n}^{\circ}$ obs. High & & 30 & & 25 & 7 & 64 & 37 & 20 & 112 & 34 & 39 & 50 & 20 & 5 \\
\hline $\mathrm{n}^{\circ}$ obs. Total & & 90 & & 75 & 22 & 192 & 111 & 62 & 336 & 104 & 119 & 150 & 60 & 15 \\
\hline
\end{tabular}


Table 2: Pension Expenditures in European Countries ( $\%$ of GDP)

\begin{tabular}{|c|c|c|c|c|c|c|c|c|c|c|c|c|c|c|}
\hline Country & Germany & Denmark & Netherlands & Belgium & Luxembourg & France & \begin{tabular}{|c|} 
United \\
Kingdom
\end{tabular} & Ireland & Italy & Greece & Spain & Portugal & Austria & Finland \\
\hline 1990 & 6,77 & 4,6 & 6,08 & 4,57 & 4,17 & 6,65 & 4,65 & 2,22 & 8,19 & 5,77 & 5,96 & 3,27 & 5,46 & 6,06 \\
\hline 1991 & 6,98 & 4,69 & 6,02 & 4,77 & 4,55 & 6,95 & 4,91 & 2,18 & 8,34 & 5,88 & 6,13 & 3,44 & 5,56 & 7,02 \\
\hline 1992 & 7,24 & 4,73 & 5,98 & 4,77 & 4,63 & 7,15 & 4,97 & 2,13 & 9,02 & 5,58 & 6,42 & 3,55 & 5,65 & 7,84 \\
\hline 1993 & 7,47 & 4,78 & 5,97 & 4,9 & 4,79 & 7,54 & 4,93 & 1,97 & 9,23 & 5,64 & 6,96 & 3,77 & 5,9 & 7,71 \\
\hline 1994 & 7,57 & 5,71 & 5,59 & 4,85 & - & 7,52 & 4,68 & 1,82 & - & - & 7,04 & 3,88 & 5,92 & 7,49 \\
\hline 1995 & 7,71 & 5,63 & 5,54 & - & - & 7,59 & - & 1,63 & - & - & 7,13 & 3,95 & 5,93 & 7,28 \\
\hline $1996-$ & & 5,49 & 5,52 & - & - & - & - & 1,5 & - & - & $5^{-}$ & 4,03 & - & - \\
\hline
\end{tabular}


Table 3. Replacement rates for low income individuals

\begin{tabular}{|c|c|c|c|c|c|c|c|c|c|c|c|c|c|c|}
\hline & Germany & Denmark & Netherlands & Belgium & Luxembourg & France & $\begin{array}{c}\text { United } \\
\text { Kingdom }\end{array}$ & Ireland & Italy & Greece & Spain & Portugal & Austria & Finland \\
\hline \begin{tabular}{|l} 
Replacement \\
Rate bottom \\
$33,33 \%$ \\
\end{tabular} & n.a. & 1,2749 & n.a. & 0,9208 & 3 & 1,0295 & 2,1667 & 0,7084 & 1,0500 & 0,9722 & 1,0707 & 1,2177 & 1,0303 & 1,3495 \\
\hline$n^{\circ}$ obs. & & 30 & & 25 & 7 & 64 & 37 & 21 & 112 & 35 & 40 & 50 & 20 & 5 \\
\hline $\begin{array}{l}\text { Replacement } \\
\text { Rate bottom } \\
20 \% \\
\end{array}$ & n.a. & 2,0017 & n.a. & 1,3171 & 3 & 1,2169 & 2,3067 & 0,7566 & 1,5648 & 1,2850 & 1,1567 & 1,4682 & 1,7864 & 1,5040 \\
\hline$n^{\circ}$ obs. & & 18 & & 15 & 5 & 38 & 22 & 12 & 67 & 19 & 24 & 30 & 12 & 3 \\
\hline
\end{tabular}


Table 4: Measures of Inequality in European Countries

\begin{tabular}{|c|c|c|c|c|c|c|c|c|c|c|c|c|c|c|}
\hline Country & Germany & Denmark & Netherlands & Belgium & Luxembourg & France & $\begin{array}{c}\text { United } \\
\text { Kingdom }\end{array}$ & Ireland & Italy & Greece & Spain & Portugal & Austria & Finland \\
\hline $\begin{array}{l}\text { Gini } \\
\text { index }\end{array}$ & 30 & 24,7 & 32,6 & 25 & 26,9 & 32,7 & 36,1 & 35,9 & 27,3 & 32,7 & 32,5 & 35,6 & 23,1 & 25,6 \\
\hline $\begin{array}{l}\text { Lowest } \\
20 \%\end{array}$ & 8,2 & 9,6 & 7,3 & 9,5 & 9,4 & 7,2 & 6,6 & 6,7 & 8,7 & 7,5 & 7,5 & 7,3 & 10,4 & 10 \\
\hline $\begin{array}{l}\text { II+III+IV } \\
20 \%\end{array}$ & 53,4 & 55,9 & 52,6 & 56 & 54,1 & 52,6 & 50,4 & 50,4 & 55 & 52,2 & 52,2 & 49,3 & 56,3 & 54,2 \\
\hline $\begin{array}{l}\text { Highest } \\
20 \%\end{array}$ & 38,4 & 34,5 & 40,1 & 34,5 & 36,5 & 40,2 & 43 & 42,9 & 36,3 & 40,3 & 40,3 & 43,4 & 33,3 & 35,8 \\
\hline $\begin{array}{l}\text { Survey } \\
\text { year }\end{array}$ & 1994 & 1992 & 1994 & 1992 & 1994 & 1995 & 1991 & 1987 & 1995 & 1993 & 1990 & 1994-95 & 1987 & 1991 \\
\hline
\end{tabular}


Table 5: Second pillar and financial indicators

\begin{tabular}{|c|c|c|c|c|c|c|c|c|c|c|c|c|c|c|}
\hline Country & Germany & Denmark & Netherlands & Belgium & Luxembourg & France & $\begin{array}{c}\text { United } \\
\text { Kingdom }\end{array}$ & Ireland & Italy & Greece & Spain & Portugal & Austria & Finland \\
\hline $\begin{array}{l}\text { Pension funds } \\
\text { assets as } \\
\% \text { GDP (1993) }\end{array}$ & 5,8 & 20,1 & 88,5 & 3,4 & n.a. & 3,4 & 79,4 & 40,1 & 1,2 & n.a. & 2,2 & n.a. & n.a. & n.a. \\
\hline $\begin{array}{l}\text { Supplementary } \\
\text { pension as \% } \\
\text { of total pension } \\
(1993)\end{array}$ & 11 & 18 & 32 & 8 & na & 21 & 28 & 18 & 2 & n.a. & 3 & n.a. & n.a. & n.a. \\
\hline \multicolumn{15}{|c|}{ Source: Green Paper EC 1997. Based on European Federation for Retirement Provision (EFRP)-European Pension Funds 1996} \\
\hline Country & Germany & Denmark & Netherlands & Belgium & Luxembourg & France & $\begin{array}{c}\text { United } \\
\text { Kingdom }\end{array}$ & Ireland & Italy & Greece & Spain & Portugal & Austria & Finland \\
\hline $\begin{array}{l}\text { Pension funds } \\
1984-93 . \\
\text { Average } \\
\text { Nominal Rates } \\
\text { of Return (Real } \\
\text { in parenthesis) }\end{array}$ & $9,4(7,1)$ & $10(6,3)$ & $9,5(7,7)$ & $11,8-(8,8)$ & n.a. & n.a. & $15,5(10,2)$ & $14(10,3)$ & n.a. & n.a. & $13,8(7)$ & n.a. & n.a. & n.a. \\
\hline $\begin{array}{l}\text { Market } \\
\text { capitalization in } \\
\% \text { of GDP } \\
(1996)\end{array}$ & 29,6 & 41,8 & 97,8 & 45,9 & 193,4 & 38,9 & 149,9 & 49,7 & 21,7 & 19,7 & 42,3 & 23,7 & 14,3 & 50,7 \\
\hline
\end{tabular}

